\title{
ADVERSITY QUOTIENT: SURVIVING RATHER THAN GIVING UP
}

Dr. Nidhi Chadha, Assistant Professor, Department of Psychology, Goswami Ganesh Dutta Sanatan Dharma College, Sector -32 , Chandigarh

\begin{abstract}
Every day, people experience different adversities in life. They often face specific events that may challenge their psychological stability as individuals. Such adversities may be in the form of sudden loss of a loved one, loss of job, financial instability, strained relationships, career insecurities and other events that may leave a great impact not just on the temporary emotional state of an individual but also, may affect the individual's long-term psychological state. Nevertheless, each of us has the God-given inner ability to face and solve such terrible situations to advantage in life. Despite exposures to stress, some people can withstand, overcome, and be strengthened and successful by the negative experience. In the present times, this pertinent psychological issue can be addressed as 'Adversity Quotient (AQ) i.e. the science of human resilience'. People who successfully apply AQ in their life will perform optimally in difficulties, challenges- small or big- that confront them every day. This research paper tries to explore how individuals deal with such adversities and are able to bounce back as stronger and wiser amidst certain events in their life that brought tremendous change to their psychological well-being. Also, this research endeavors to provide an insight to educators, counsellors, parents and students how to surmount life adversities and survive rather than giving up in life.
\end{abstract}

Keywords

Adversities, Psychological well-being, Resilience

\section{Introduction}

The Adversity Quotient makes people go through a rough patch in life and come out without losing their centres. The AQ determines who will give up in face of troubles, who will abandon their family or who will consider suicide.

To begin with the term 'Adversity Quotient', Dr. Paul Stoltz (1997) coined it in his book 'Adversity Quotient: Turning Obstacles Into Opportunities'. AQ measures one's ability to prevail in the face of adversity. It explains how one responds to difficult situations and how one rises above difficulties. Stoltz (1997) said that "life is like mountain climbing and that people are born with a core human drive to ascend". Ascend means moving your purpose forward in life no matter what your goals are. AQ is the underlying factor that determines one's ability to ascend (Stoltz, 2000). According to Ari (2011), adversity quotient is an intelligence that one possesses to overcome difficulties in order to survive. Adversity Quotient is the level of a person's ability to survive and pass through all the difficulties in their daily lives to achieve the success that everyone wants. Phoolka $\&$ Kaur (2012) gave their indigenous perspective which posits that Adversity Quotient (AQ) is a very useful new paradigm as challenges arise in all walks of life.

Adversity Quotient comprises of five different components called the CO2RE dimensions which are as follows:

$>$ The Control (C) dimension measures the control, as perceived by an individual, over an adverse event.

$>$ The Origin (O) and Ownership (O)measures what or who an individual sees as the origin of the adverse situation and how much does he see himself responsible for the same.

$>$ The Reach $(\mathrm{R})$ dimension measures the spillover effect of the adversity into the other areas of the person's life i.e. whether or not the consequences of current adversity will have any bearing on the person's other aspects of life.

$>$ The Endurance (E) dimension is the time span in which one expects the adversity to last.

\section{The Origin of Adversity Quotient}

We each have a distinct explanatory style or pattern of responding to life's events. The nature of the 
pattern determines how we react and all that follows: for example, those who believe that a given setback is far-reaching and long-lasting are more likely to believe that what they do will not matter. This pattern is also known as Learned Helplessness.

Seligman (1990) says that those with such destructive response patterns are a group of people who would say, It is going to last forever, going to undermine everything I do, and it's my fault. However, those who perceive the same setback as limited and fleeting are more likely to respond to the challenge positively and optimistically. The research of the positive psychologist Seligman clearly indicates that these patterns are learned. More important, it has been determined that these patterns can be permanently rewired and strengthened.

These discoveries contribute to our understanding of the Adversity Quotient. AQ is the next generation of understanding how we explain or respond to life's events. Patterns such as AQ is learned and hardwired into our brain during your impressionable youth when we watch others deal with life's difficulties. As any individual unconsciously absorb and adapt these responses, he or she automatically chooses unique response pattern, or AQ.

\section{The Levels of Adversity}

Stoltz (1997) outlines three levels of adversity which he labels the societal, the workplace and the individual adversity. Firstly, Societal adversity entails the experience of profound shift in wealth, the problems of upsurge in crime and violence while belief in the system and institutions is decreasing, in addition there is a drastic change in how family and home is defined, and a lack of security both when it comes to economy and the future in general. Secondly, workplace in the new millennia is demanding ever more of their workers in order to stay on top of the game. But while more is required to reach the desired goals less is gained. In addition, constant changes in the workplace make no promises of long-term employment, which in turn can lead to mounting frustrations, all of which brings about what Stoltz calls workplace adversity. Thirdly, it is the individual that eventually ends up carrying the burden; and the net results of the accumulated weight of societal and workplace adversity makes for the individual adversity.

As described by Stoltz (2000), people face such adversities everyday and eventually, if these adversities are not met with sufficient capacity in the form of higher-level skills and accessible wisdom, these growing adversities may become too much to handle. Particularly at work these daily annoyances can lead to depression, making it difficult for individuals who feel it is hopeless to perform optimally and can seriously undermine a worker's capacities and willingness to face challenges.

\section{Adversity Quotient in Relation to Positive Psychology}

According to Ryff (1989), a convergence of multiple frameworks of positive functioning served as the theoretical foundation to generate a multidimensional model of well-being. Six distinct components of positive psychological functioning are incorporated by individuals who are high on Adversity Quotient. These dimensions encompass a breadth of wellness that includes the following:

$>$ Self-acceptance: This is defined as a central feature of mental health as well as a characteristic of self-actualization, optimal functioning, and maturity. It is the positive evaluations of one's self and one's past life.

$>$ Personal growth: A sense of continued growth and development as a person. Optimal psychological functioning requires not only that one achieves the prior characteristics, but also that one continue to develop one's potential, to grow and expand as a person

$>$ Purpose in life: The belief that one's life is purposeful and meaningful. Mental health is defined to include beliefs that gives one the feeling regarding the purpose and 
meaning to life. Thus, one who functions positively has goals, intentions, and a sense of direction, all of which contribute to the feeling that life is meaningful.

Positive relations with others: The possession of quality relations with others. The ability to love is viewed as a central component of mental health. Many of the theories emphasized the importance of warmth and trust in interpersonal relationships.

Environmental mastery: The capacity to manage effectively one's life and surrounding world. The individual's ability to choose or create environments suitable to his or her psychic conditions is defined as a characteristic of mental health.

Autonomy: The fully functioning person is described as having an internal locus of evaluation, whereby one does not look to others for approval, but evaluates one's self by personal standards.

\section{Adversity Quotient and Self Efficacy}

Self Efficacy, as developed by Albert Bandura, relates to a person's beliefs in his or her capacity to master the needed motivation, cognitive resources, and courses of action in order to meet given situational demands (Chen, Gully \& Eden, 2001). The control dimension of Adversity Quotient signifies how well a person believes he or she is capable of positively influencing a situation. If, for instance, an individual believes he is unable to gather the necessary behavioural, cognitive and motivational resources to carry out a given task, then he or she will most likely feel the task as too daunting. The lack of self-confidence will in turn cause the individual to put forth too little effort to be able to succeed in the task. In Stoltz' model lack of control causes loss of hope and a decrease in the willingness to take action (Stoltz, 1997). Selfefficacy plays a crucial role in social cognitive theory developed by Albert Bandura. The theory identifies several basic human means by which cognitive processes related to motivation operates to initiate, execute, and maintain work behaviour (Stajkovic \& Luthans, 2003). According to the theory self-efficacy beliefs vary on three dimensions believed to be crucial for human performance in organizations. The first is the magnitude of self-efficacy beliefs related to the level of task difficulty. The second dimension is the strength of self-efficacy which speaks to an individual's confidence in successfully executing a particular level of task difficulty. The third dimension is generality and is related to the extent to which the strength of self-efficacy beliefs can be said to generalize across tasks and situations.

\section{Adversity Quotient in Relation to Types of Personality}

Adversity Quotient describes three types of personalities, these being the Climbers, the Campers and the Quitters.

$>$ Climbers are people who continuously seek for improvement and growth. They live to get the utmost out of life, are selfmotivated and highly driven. They embrace challenges, are highly visionary people and are often an inspirational source to others (Angelopoulos \& Co., 2002).

$>$ Campers are, by definition, people who have stopped moving forward in life as they have become weary of life's many obstacles. As such, they have settled for what they think is good enough, rarely ever taking on bigger challenges. Campers are, in other words, people who are satisfied with the current state of affairs, letting greater opportunities pass them by. They will invest as much as is necessary to keep things satisfactory.

$>$ Quitters are people of minimal drive and little ambition. They are rarely creative, do not like to take risks and tend to avoid challenges. 


\section{Adversity Quotient in Relation To Personality \\ Traits}

Adversity Quotient is highly correlated with two of the Big Five traits as given by McCrae \& Costa, these being Emotional Stability and Conscientiousness. According to Stoltz, AQ defines an individual's way of handling negative and stressful events. One of the Big Five dimensions i.e. Emotional Stability describes the same phenomenon. Individuals scoring high on Emotional Stability are thought to be less prone to worry about and dwell on negative things. Emotional Stability is related to at least two tendencies; how people deal with Anxiety and; the way people cope with the many stresses that life poses.

Similarly, the Big Five's Conscientiousness dimension is thought to be associated with $\mathrm{AQ}$. Individuals scoring high on Conscientiousness are related to planfulness and achievement striving (Barrick \& Mount, 2003) which would also make them more likely to exert greater effort and be more committed to their goals. Such individuals are known to be hardworking and persistent, often driven by the need for getting ahead. The key aspects of Conscientiousness have generally been found to be achievement, order, cautiousness, and dependability. Achievement is strongly associated with competence and success in one's work. This entails the ability to always set high standards for one's performance and to constantly work to achieve one's goals. It involves being careful, planful, wellorganized, thorough, detail-oriented (Dudley et al., 2006).

Further, clearly there is some overlap between that of being a Climber and a Conscientious individual. Both individuals would be described as highly industrious and both would be willing to invest long hours of hard work in order to achieve higher goals. The opposite should also hold true for individuals who are low on Conscientiousness and those classified as Quitters by Stoltz. Low Conscientious people do not engage in behaviours that would get them far in life, have less self- control,not of the persistent kind, and have little need for achievement. These same tendencies, as have been mentioned above, are also familiar descriptions of a Quitter.

Lastly, going by the definition, Quitters seem to be characterized by a low score on the Conscientiousness dimension, and at the lower end of the Emotional Stability dimension, while Climbers, who seem to be described as the total opposites, can perhaps be characterized at the higher end of the Conscientiousness dimension and also higher end of the Emotional Stability dimension. Campers, on the other hand, might be interpreted as scoring moderately on both the Conscientiousness and Emotional Stability dimensions.

Importance of Hardiness in Adversity Quotient Hardiness is a concept firstly developed by Suzanne Kobasa (1979), which focuses on how some people are more resistant to stress than others despite facing major stressful events. The concept is about individual differences and includes three dimensions: commitment, control, and challenge. Commitment speaks to how deep a person is involved in personal projects and goals. The more involved or engaged a person is the higher he or she is in commitment, while those low in commitment are less involved and are said to only be going through the motions. Control is a person's perceived control over important outcomes as well as the belief that it is possible to come up with solutions to whatever problems that life brings about. A person who is high in control will typically confront the problem at hand. In the same token, a person who is low in control typically leaves it to destiny; imagining either luck or faith to prevail. Challenge, the last dimension, is related to how a person interprets stressful events. For instance, a person can perceive the stressful events as either a threat to selfesteem and security, or possibly perceive the stressful events as something challenging. If so, they will not be as devastating, but rather make room for personal growth. These 
three dimensions are of crucial importance while handling adversities in life.

\section{Role of Locus of Control in Adversity Quotient}

Locus of Control is a concept concerning an individual's beliefs about the nature of rewards and punishment as a consequence of particular stimuli. That is, whether they believe the responsibility for events can be related to something internally within themselves, or whether they attribute it to something externally (Larsen \& Buss, 2007). Some individuals, for instance, believe that the causes behind events in their lives are due to luck or faith while some others again perceive the happenings in their lives as being governed by forces of some kind outside of their control (Hunt, 1993). Such beliefs are generally termed External Locus of Control.

On the other side of the coin are the individuals who perceive the events in their lives as entirely controllable by their own efforts and actions. Such a belief is called Internal Locus of Control (Judge \& Bono, 2001). The term External versus Internal Locus of Control was first proposed by Julian Rotter's (1973) Social Learning theory describes the two extreme ends of the scale in Rotter's locusof-control continuum. Individuals who perceive themselves as internally controlled are more likely to believe that reinforcement will follow certain behaviours (Barrick \& Ryan, 2003). With regards to Adversity Quotient, the Internal Locus of Control category highlights the importance of accountability; the capacity to see your own role in a given situation in order to take initiative and improve it.

\section{Final Remarks}

Adversity Quotient explains how one can withstand the challenges and their ability to overcome and handle the small and big challenges they face on a daily basis. It is a reflection of an individual facing a challenge. This intelligence can predict how well one can withstand the challenge and overcome them. Inculcating and fostering AQ can predict an individual's resilience and can also lead to an enhancement of an array of effective relationships such as groups, families, communities, cultures, societies and organizations.

\section{References}

[1] Angelopoulos, P.A., Houde, S. J.R.J., Thompson, M. M., McCreary, D. R., Blais, A.\& Pastó, L (2002), Canadian Forces Training and Mental Preparation for Adversity: Empirical Review of Stoltz's Adversity Quotient (AQ) Training for Optimal Response to Adversity' Technical Report.DRDC Toronto TR 2002-147.

[2] Bandura, A. (1995). Self-efficacy in changing societies. New York: McGrawHill.

[3] Barrick, M.R., \& Mount, M.K. (2003). Impact of meta-analysis methods on understanding. personality-performance relations In Kevin Murphy (ed.) Validity generalization: A critical review (pp. 197221). Mahwah, NJ: Lawrence Erlbaum.

[4] Chen, G., Gully, S., M., Eden, D. (2001) Validation of a new General Self-Efficacy Scale. Organizational Research Methods, 62-83.

[5] Dudley, N. M., Orvis, K. A., Lebiecki, J. E., \& Cortina, J. M., (2006) A Meta-Analytic Investigation of Conscientiousness in the Prediction of Job Performance: Examining the Intercorrelations and the Incremental Validity of narrow Traits. Journal of Applied Psychology, 91, 40-57.

[6] Hunt, M. (1993). The Story of Psychology. New York: Doubleday.

[7] Judge, T. A., Higgins Chad A., Thoresen, Carl J. \& Barrick, Murray R. (1999).The Big Five Personality Traits, General Mental Ability, and Career Success Across the Life Span. Personnel Psychology, 52.

[8] Judge, T. A, \& Bono, J. E. (2001) Relationship of Core Self-Evaluations Traits-Self- Esteem, Generalized SelfEfficacy, Locus of Control, and Emotional Stability- With Job Satisfaction and Job 
performance: A Meta-Analysis. Journal of Applied Psychology, 1, 80-92.

[9] Kobasa, S. C. (1979). Stressful Life Events, Personality, and Health: An inquiry into Hardiness. Journal of Personality and Social Psychology, 37, 1-11.

[10] Larsen, J. R., \& Buss, M. D. (2007). Personality Psychology: Domains of Knowledge About Human Nature (3rd Ed.) New York, McGraw-Hill.

[11] Phoolka, S., \& Kaur, N. (2012). Adversity quotient: a new paradigm to explore. International Journal of Contemporary Business Studies, 3(4), 67-78.

[12] Rotter, J. (1973). Internal-external Locus of Control scale. In J. P. Robinson \& R. P. Shaver (Eds.), Measures of Social psychological attitudes. Ann Arbor: Institute for Social Research.

[13] Stajkovic, A. D., \& Luthans, F. (2003) Motivation and Work Behaviour, Social Cognitive Theory and Self-Efficacy: Implications for Motivation Theory and Practice (7thed) New York, McGraw-Hill Irwin, p. 126-139.

[14] Stoltz, P. G. (1997). Adversity quotient: Turning obstacles into opportunities. New York: John Wiley and Sons, Inc.

[15] Stoltz, P.G. (2000). Adversity Quotient @ work: Make Everyday Challenges the Key to Your Success: Putting the Principles of AQ into Action. Canada: John Willey and Sons, Inc. Wiley Publishers. 